\title{
Are Macrophages in Tumors Good Targets for Novel Therapeutic Approaches?
}

\author{
Samthosh V. Alahari ${ }^{1}$, Shengli Dong, and Suresh K. Alahari ${ }^{\star}$
}

\begin{abstract}
The development of cancer has been an extensively researched topic over the past few decades. Although great strides have been made in cancer prevention, diagnosis, and treatment, there is still much to be learned about cancer's micro-environmental mechanisms that contribute to cancer formation and aggressiveness. Macrophages, lymphocytes which originate from monocytes, are involved in the inflammatory response and often dispersed to areas of infection to fight harmful antigens and mutated cells in tissues. Macrophages have a plethora of roles including tissue development and repair, immune system functions, and inflammation. We discuss various pathways by which macrophages get activated, various approaches that can regulate the function of macrophages, and how these approaches can be helpful in developing new cancer therapies.
\end{abstract}

\section{INTRODUCTION}

Macrophages are important cells of the immune system. They are derived from monocytes which enter various tissues and differentiate into macrophages. In the immune response, they use phagocytosis, a process in which the macrophages engulf pathogens, to protect the human body from disease. In addition to macrophages' importance to the general functions of the immune system, they also play various roles in cancer. These macrophages, or tumor-associated macrophages (TAMs), interact with cancer cells to cause phagocytosis and lysis of tumor cells. On the other hand, TAMs have also been discovered to be an integral part of the tumorigenic pathway. The balance of cytokines and other molecular signals determines the role of these TAMs and thus it is important to study them closely. However, it is important to note that approximately $80 \%$ of studies show an association between TAMs and protumorigenic effects while only $10 \%$ of studies show the oppo-

Department of Biochemistry and Molecular Biology, LSU School of Medicine, New Orleans, LA 70112, USA, 'McAllister Heart Institute, University of North Carolina School of Medicine, Chapel Hill, NC 27599, USA

*Correspondence: salaha@Isuhsc.edu

Received 6 November, 2014; accepted 9 November, 2014; published online 16 December, 2014

Keywords: angiogenesis, cancer, invasion, macrophages, microenvironment, migration site effect.

Before delving into TAMs' function in cancer, it is important to understand the general cancer process. Cancer can be broken into three distinct stages. In the first stage, cancerous cells invade an area's surrounding tissues and blood vessels; this area is referred to as the primary site. In the second stage, the cancer cells begin to move to secondary sites through the circulatory system. In the third and final stage, the cancer cells invade the secondary site's surrounding tissues and blood vessels. This cycle can then repeat yielding tertiary sites and so forth. Once the primary site is established, tumor development is spurred by angiogenesis. Hanahan and Weinberg (2000), created a model that lays out the six properties that a tumor acquires while growing. These properties include an ability to replicate endlessly, angiogenesis, evasion of apoptosis, creating its own growth signals, insensitivity to growth inhibitors, and tissue invasion and metastasis. A seventh property, tumor microenvironment inflammation, was later added to the model (Hanahan and Weinberg, 2000; Mantovani, 2009) (Fig. 1). Here we discuss the mechanisms by which macrophages get activated and their important role in tumor progression.

\section{TUMOR ASSOCIATED MACROPHAGES AND RELATED MOLECULES}

Two different types of phenotypes for macrophages have been described; these include: M1 and M2. The M1 phenotype is associated with active microbial killing while the M2 phenotype is associated with angiogenesis and wound repair. TAMs can typically be identified by low expression of tumor necrosis factors (TNF) and high expression of IL-1 and IL-6. Specifically M1 macrophage polarization is caused by interferon gamma (IFNgamma) and TNF- $\alpha$ secretion by T helper 1 (Th1) lymphocytes or natural killer (NK) cells (Gordon, 2003; Martinez et al., 2009; Murray and Wynn, 2011). Interferon (IFNs) or toll-like receptor (TLR) signals can produce the M1 phenotype through the STAT1 signaling pathway. M1 macrophages also produce chemical attractants, such as pro-inflammatory cytokines, interleukin-12 (IL-12), IL-1 $\beta$, and IL-6 (Heusinkveld and van der Burg, 2011; Porta et al., 2011). M2 macrophages, on the other hand, are activated by Th2. Th2 releases several cytokines, such as IL-4, IL-10, and IL-13, to activate the M2 macrophages (Gordon, 2003; Murray and Wynn, 2011). The M2 macrophage phenotype is caused by IL-4 and IL-13 via the STAT6 signaling pathways. In addition, Kruppel-like factor 4 (KFL4) works in conjunction with STAT6 to produce M2 genes, while inhibiting $\mathrm{M} 1$ genes through isolation of some NF-kB activators. Unlike 


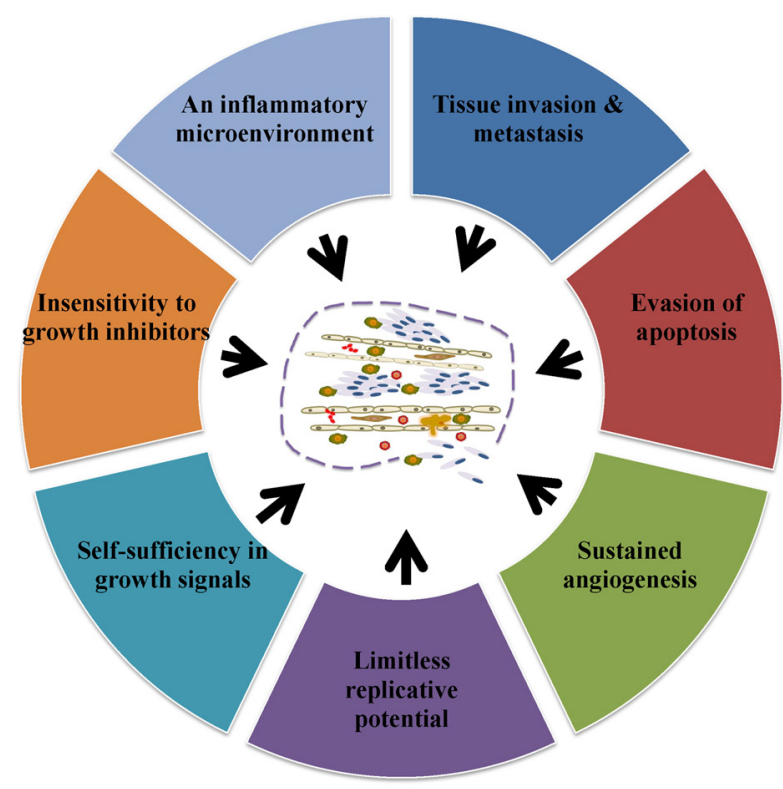

Fig. 1. The major steps involved in cancer. This model depicts essential steps during cancer progression. These steps include continuous replication, developing new blood vessels, self- sufficiency of growth signals, insensitivity to growth inhibitors, formation of inflammatory microenvironment, promotion of tissue invasion and metastasis, and evasion of apoptosis (Adapted from Mantovani, 2009).

the $\mathrm{M} 1$ phenotype, the $\mathrm{M} 2$ phenotype can be divided into 3 more categories: M2a, M2b, and M2c. M2a is differentiated by $\mathrm{IL}-4$ and IL-13 while M2b by immune complexes. M2c is differentiated by IL-10 and also plays a role in immunosuppression and tissue remodeling (Hagemann et al., 2009). Furthermore, it has been shown that Th1 cytokines produce M1 macrophages while M2 macrophages play a role in Th1 adaptive immunity suppression, resolution of inflammation, parasite protection, wound healing promotion, angiogenesis, and tissue remodeling (Biswas and Mantovani, 2010).

Some of the most potent macrophage activators of metastasis involved in Lewis lung carcinoma lead to the production of IL-6 and TNF- $\alpha$ through the activation of essential-tometastasis TLR2 and TLR6 (Chiodoni et al., 2010; Kim et al., 2009). These macrophages are recruited to tumor cells by the production of monocyte chemotactic protein (MCP), macrophage-colony stimulating factor (M-CSF), vascular endothelial growth factor (VEGF), angiopoietin 1 (ANG1), and ANG2. In addition to macrophage recruitment, VEGF, ANG1, and ANG2 play roles in promoting angiogenesis (Pollard, 2004). Antiinflammatory molecules, such as IL-4, IL-10, transforming growth factor beta 1 (TGF- $\beta 1$ ), and prostaglandin E2 (PGE2) produced by tumor cells cause macrophages to attain the M2 phenotype. Adding IL-10 in vitro inhibits production of proinflammatory cytokines and chemokines (Kim et al., 1995). IL-10 also reduces surface expression of major histocompatibility complex II (MHCII) and co-stimulatory molecules CD80 and CD86 resulting in immunosuppression (Moore et al., 2001). Additionally, IL-10 interacts with IL-4 to cause Arginase-1 expression in macrophages (Lang et al., 2002). The source of this $\mathrm{IL}-10$ is not yet known, but PGE2, which is produced by tumor cells, has been shown to effect TAM polarization along with
EP4 receptors (Akaogi et al., 2004; Heusinkveld et al., 2011; Kambayashi et al., 1995). TLRs, such as TLR2 and TLR4, cause cytokines to become proinflammatory and thus polarize TAMs. The production of proteases by TAMs, such as urokinase type plasminogen activator (UPA) and MMP-9, further enhance tumor invasion by breaking down the basement membrane and remodeling the stromal matrix (Huang et al., 2002; Stetler-Stevenson and Yu, 2001; Wang et al., 2005). Epidermal growth factor (EGF), TGF- $\beta$, IL-8, and TNF- $\alpha$ all play roles in the migration of tumor cells in addition to protecting the tumor cells by providing them with proliferative and anti-apoptotic signals. TGF- $\beta 1$ derived from macrophages also caused greater expression of matrix metalloproteinase 9 (MMP-9) in glioma stem-like cells which has been shown to increase tumor cell invasiveness (Ye et al., 2012). MMP-9 also causes the release of VEGF-A, a precursor to angiogenesis. In addition, M2 macrophages express a truncated fibronectin isoform, migration-stimulation factor (MSF), which has a large chemotactic effect on tumor cells. Depletion studies conducted by Denardo et. al and Joyce and Pollard showed reduced levels of metastasis as well (DeNardo et al., 2009; Joyce and Pollard, 2009). Furthermore, macrophages that are attracted to inflammation or tissue breakdown sites have been shown to promote tumorigenesis by synthesizing estrogens (Figs. 2 and 3 ).

Looking further into VEGF, it has been determined that it is an angiogenic factor that triggers angiogenesis and lymphangiogenesis. Angiogenic and lymphangiogenic factors include VEGF-A, VEGF-C, VEGF-D, and MMP that all bind to their respective coordinating receptors and play roles in enhancing endothelial cell proliferation, migration, and tube-like formation (Giraudo et al., 2004; Wu et al., 2012). MMP has also been shown to mediate VEGF-A levels in some studies. Specifically, MMPs are proteolytic enzymes tasked with the degradation of proteins within the extracellular matrix. They regulate many cell behaviors within the tumor microenvironment (Egeblad and Werb, 2002).

The importance of lymphangiogenesis must not be understated because it plays a large role in tumor stability and growth even though it occurs second to angiogenesis in a tumor. Lymphangiogenesis exposes the tumor to immune cells leading to lymphatic metastasis and without it, the tumor would likely stop growing and be destroyed (Kurahara et al., 2012). Lymphangiogenesis is typically induced by VEGF-A and VEGF C/D binding with VEGFR-2 and VEGFR-3 receptors. In addition, tissue inflammation in tumors has been shown to expand lymph nodes and lead to increased lymphangiogenesis and lymphoid hyperplasia. Inhibition of M-CSF has been shown to suppress tumor lymphangiogenesis since it plays a role in VEGF-A/C secretion. Interestingly, endothelial nitric oxide synthase (eNOS) and IL-6 also regulate lymphangiogenesis (Ji, 2011) (Fig. 3).

Research has shown that there is a positive correlation between the number of TAMs and advanced tumor progression and metastasis. Many tumors show overexpression of M-CSF and when down-regulated, there is a decrease in macrophage activity. Knocking out MCP has led to lower levels of macrophages and decreased tumor progression as well. These data demonstrate a clear relationship between TAMs and tumorigenesis. Surprisingly, further overexpression of MCP has shown that at a certain point, M1 macrophages are attracted to the site causing cytotoxic effects on the tumor cells (Shirabe et al., 2011).

In addition to the decrease in macrophage activity due to the downregulation of M-CSF, vascularization is also reduced. Without vascularization, larger tumors struggle to grow due to 

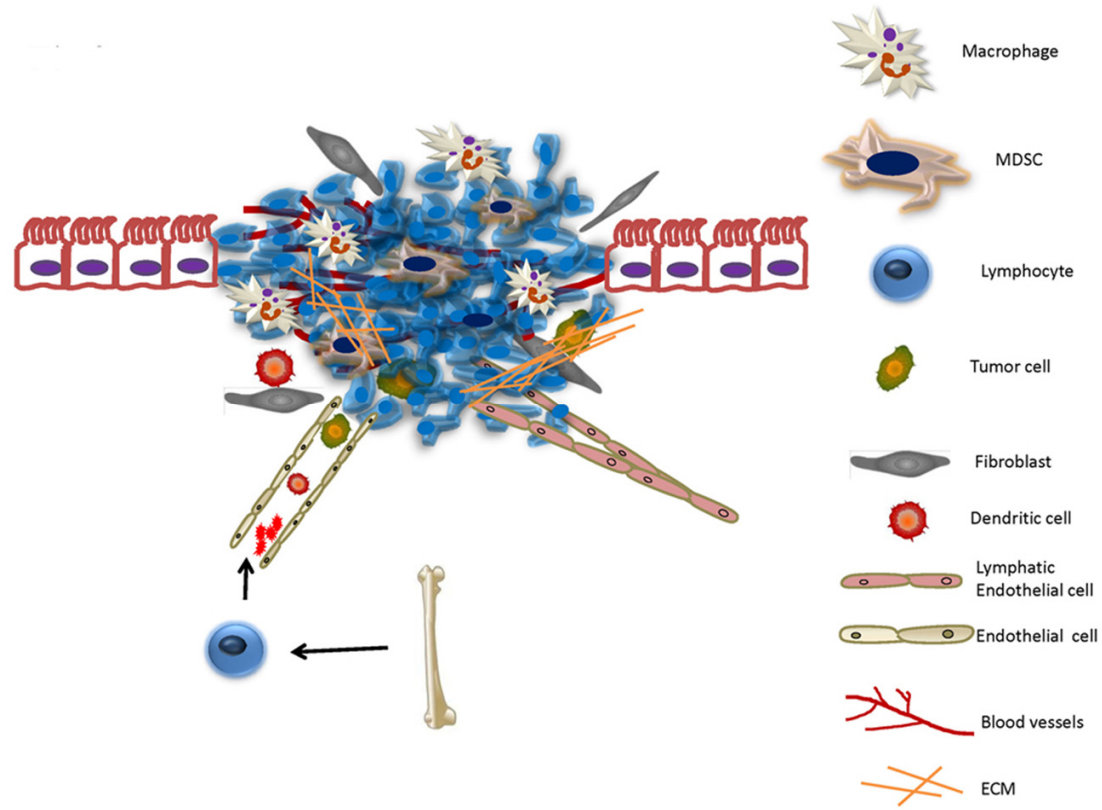

Metastasis

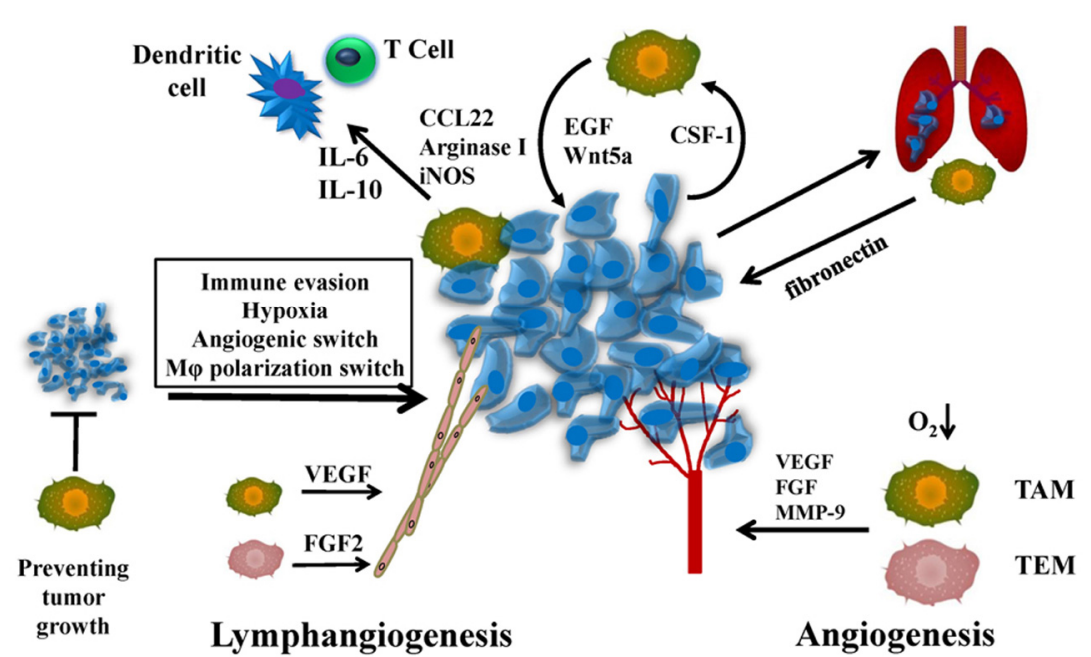

Fig. 2. The tumor microenvironment. It is created the moment the tumor becomes attached to a site and encompasses the extracellular matrix surrounding the tumor cell and any non-cancerous cells. This microenvironment is composed of endothelial cells, stromal cells, bone marrow derived cells, macrophages and TIE2-expressing monocytes and myeloid derived suppressor cells.
Fig. 3. Macrophage functions in the tumor microenvironment with special emphasis on immunosuppression, metastasis, lymphangiogenesis and angiogenesis. During immunosuppression, TAM generated molecules prevent the accumulation of cytotoxic $T$ cells (anti-tumorigenic cells). During metastasis, tumor cells secrete soluble factors that prime specific cells such as macrophages that help in seeding tumor cells at distant locations. In hypoxic areas, TAMs and TEMs (Tie2-expressing monocytes) upregulate several angiogenic factors that promote angiogenesis. During lymphangiogenesis, TAMs secrete various factors that initiate the formation of lymphatics. insufficient amounts of oxygen causing hypoxic regions. TAMs compensate for this effect by congregating in these areas causing upregulation of certain transcription factors that lead to the expression of various growth factors, cytokines, and other signaling molecules resulting in angiogenesis (Obeid et al., 2013). These transcription factors cause secretion of VEGF and basic fibroblast growth factor (bFGF) which promote the proliferation and maturation of endothelial cells (Lamagna et al., 2006; Siveen and Kuttan, 2009). TAM created proteases, such as MMPs, plasmin, and urokinase plasminogen activator, degrade and remodel the extracellular matrix leading to further angiogenesis (Siveen and Kuttan, 2009).

The majority of research indicates increased levels of TAM activity result in a negative prognosis. The M1 phenotype is usually present during early stages of tumor development while the M2 phenotype is associated with more advanced tumors. In addition, compounds such as VEGF and M-CSF allow for tumor development to progress by recruiting macrophages to the tumor site and initiating angiogenesis and lymphangiogenesis.

\section{TUMOR MICROENVIRONMENT AND MACROPHAGES}

The tumor microenvironment is a niche that has been shown to affect tumor activity and outcome. It is created the moment the tumor becomes attached to a site and encompasses the extracellular matrix surrounding the tumor cell and any non-cancerous cells that happen to reside in the targeted organ (Fig. 2).

Colony stimulating factor 1 (CSF1) and chemokine ligand 2 (CCL2) in the blood recruit monocytes that become TAMs in the tumor microenvironment, a process called intraepithelial 
neoplasia. In addition to CSF-1, the cytokines VEGF and PDGF and chemokines CCL2, CCL5, and CCL8 all attract monocytes to the tumor microenvironment (Allavena et al., 2008; Goede et al., 1999; Mantovani et al., 2008; Pollard, 2004) (Fig. 3). It may be important to note that CCL2 upregulation is caused by a RAS mutation (Qing et al., 2012). Consequently, overexpression of CSF-1 has led to a poor prognosis in patients with breast, endometrial, and ovarian cancers (Pollard, 2004; 2009). CSF-1 also interacts with IL- 6 causing the maturation of dendritic cells creating a tumor microenvironment in which the tumor's progression to metastasis is easier. Interestingly, CSF-1 in a trans-membrane form on the tumor surface has been shown to activate macrophages that kill tumor cells. Transmembrane CSF-1 with higher concentrations of IL-4, IL-12, IL13 , and granulocyte-macrophage colony-stimulating factor (GMCSF) causes dendritic cells to mature as well; however, this leads to the presentation of tumor antigens to cytotoxic $T$ cells resulting in the killing of the tumor (Pollard, 2004). By producing growth factors such as VEGF, TAMs assist the transition from intraepithelial neoplasia to an early carcinoma. While the carcinoma develops, TAMs continue to be activated allowing them to promote angiogenesis, cell invasion, intravasation, and immunosuppression. These abilities are due to the fact that TAMs are immobilized in hypoxic or necrotic regions of human tumors and, thus, TAMs upregulate hypoxia inducible factor $1 \alpha$ (HIF$1 \alpha$ ) and HIF-2 $\alpha$ (Raica et al., 2009). TAMs specifically promote angiogenesis with the help of Tie2-expressing monocytes (TEMs) and tumor cells themselves by upregulating angiogenic growth factors and enzymes to stimulate endothelial cells in the healthy surrounding areas to proliferate, migrate, and differentiate into the vessels in the tumor site (Coffelt et al., 2009). Evidence has shown that the tumor microenvironment is immunosuppressive causing the tumor to go unnoticed by the immune response. For example, M-CSF has been shown to render unable macrophages' ability to present antigens. TAMs also produce immunomodulatory cytokines and growth factors that assist in immunosuppression (Galdiero et al., 2013). Typically, this occurs at the primary site or locations where lymphocytes mature, such as lymph nodes. TAMs also show immunosuppressive activity through their modulation of TGF- $\beta$, iNOS, Arginase-1, IDO, and IL-10 (Hagemann et al., 2006; Mantovani and Sica, 2010; Sica et al., 2000; Zhao et al., 2012a; 2012b). For instance, Arginase-1 and iNOS expression causes T cell suppression in mouse models of breast cancer (Bronte and Zanovello, 2005; Chang et al., 2001; Doedens et al., 2010; Movahedi et al., 2010). TAMs have also been shown to express B7-H1 in hepatocellular carcinoma, B7-H4 in ovarian and lung cancers, and $\mathrm{B} 7-\mathrm{H} 3$ in lung cancer on tumor cell surfaces which make it easier for the tumor cells to not be susceptible to immune response (Chen et al., 2012). These cytokines change the expression of genes by regulating NF- $\mathrm{KB}$, a transcription factor, in addition to STAT1 and STAT3. Thus, the recruitment of antitumorigenic cells is downregulated resulting in a decrease of essential components of antigen-presenting. This inability to perform these functions affects the cytokine and protein profile of the tumor microenvironment, which plays a large role in determining the phenotype of local phagocytes (Coffelt et al., 2009).

\section{TUMOR ASSOCIATED MACROPHAGE REGULATION BY TRANSCRIPTION FACTORS}

It has been reported that some transcription factors also regulate TAM functions. Nuclear factor- $\kappa B(N F-\kappa B)$ is activated by
TNF- $\alpha$, IL-1, and IKK $\beta$. NF- $\mathrm{KB}$ refers to a family of transcription factors that plays a role in inflammation and immunity. NF- $\kappa B$ operates by causing the expression of pro-inflammatory cytokines, chemokines, and angiogenic factors (Porta et al., 2011). Thus NF- $\mathrm{KB}$ is an important part of the regulation of TAM function. Transcription factors for NF- $\mathrm{KB}$ include Re1A (p65), c-Rel, $\mathrm{RE} 1 \mathrm{~B}, \mathrm{p} 50$, and $\mathrm{p} 52$. Out of those transcription factors, only Re1A, Re1B, and c-Rel can activate gene transcription (Hagemann et al., 2009). NF-KB is activated primarily by IKK $\beta$ (Maeda et al., 2005). Another activator of NF-kB is hypoxia, a common marker of tumors (Rius et al., 2008). Activating NF- $\kappa B$ in inflammatory macrophages releases cytokines, interleukins, and TNF- $\alpha$. It has been shown in breast cancer cells that secretion of TNF- $\alpha$, activation of NF- $\mathrm{KB}$, and presence of JNK leads to a more invasion and tumor progression. Inhibition of NF- $\kappa B$ also directly leads to lower levels of VEGF, impeding angiogenesis. $I_{\kappa} \mathrm{B} \alpha$ is a prominent inhibitor of NF- $\kappa \mathrm{B}$ and results in decreased tumor formation when it is overexpressed (Pikarsky et al., 2004). Interestingly, it has also been shown that low levels of NF- $\mathrm{KB}$ activation results in macrophages acquiring the M2 phenotype. A theory explaining this discrepancy is that NF$\kappa \mathrm{B}$ may have a different role depending on the stage and location of the TAMs within a tumor. This was shown in epithelial cells when IKK $\beta$ was knocked out and inflammation decreased, while in myeloid cells, inflammation was increased (Fong et al., 2008; Lawrence et al., 2001). In contrast, some reports indicate that targeted NF- $\mathrm{KB}$ activation can induce apoptosis of hepatocytes while decreasing tumor size, suggesting multiple roles of NF-kB (Greten et al., 2004; Hagemann et al., 2008; Luedde et al., 2007; Maeda et al., 2005; Naugler et al., 2007; Swain and Arezzo, 2008).

\section{TUMOR ASSOCIATED MACROPHAGE REGULATION BY HYPOXIA}

There have been many studies examining the effect of hypoxia on TAMs within the tumor microenvironment (Fig. 4). Low levels of tissue oxygenation induce TAM differentiation of macrophages (Erler et al., 2009; Shen et al., 2012). HIF activation has been determined to promote tumorigenesis due to higher levels of angiogenesis, cell proliferation, and TAM differentiation. There are 3 types of HIFs: HIF- $1 \alpha,-2 \alpha$, and $-3 \alpha$. HIF- $1 \alpha$ is an important part of TAM response to hypoxia due to its ubiquitous expression and its induction of many hypoxia-inducible genes (Rankin and Giaccia, 2008). VEGF and CXCL12 are dependent on HIF-1 $\alpha$ (Knowles and Harris, 2007). HIF-1 $\alpha$ also regulates CSF-1. NF- $\kappa B$ can be modulated to regulate HIF-1 $\alpha$ (Murdoch et al., 2004). Furthermore, deletion of HIF-1 $\alpha$ has shown reduced tumor growth (Shen et al., 2012). Hypoxia causes HIF- $1 \alpha$ to upregulate genes such as VEGF, bFGF, IL$1 \beta$, IL-8, cyclooxygenase 2 (COX2), MMP-7, MMP-9, MMP-12, and ANG-1 which lead to macrophages assuming the M2 phenotype and formation of a vascular system and malignant transition (Murdoch and Lewis, 2005; Murdoch et al., 2008). Increased HIF-2 $\alpha$ expression in macrophages leads to angiogenesis and worse survival (Leek et al., 2002). Accordingly, TAMs with the highest levels of HIF-2 $\alpha$ indicate high-grade breast cancers (Leek et al., 2002). Without HIF-1 $\alpha$, the suppressive capabilities of TAMs were reduced while without HIF-2 $\alpha$, there was less TAM recruitment in inflammatory hepatocellular and colon carcinoma models (Imtiyaz et al., 2010). 


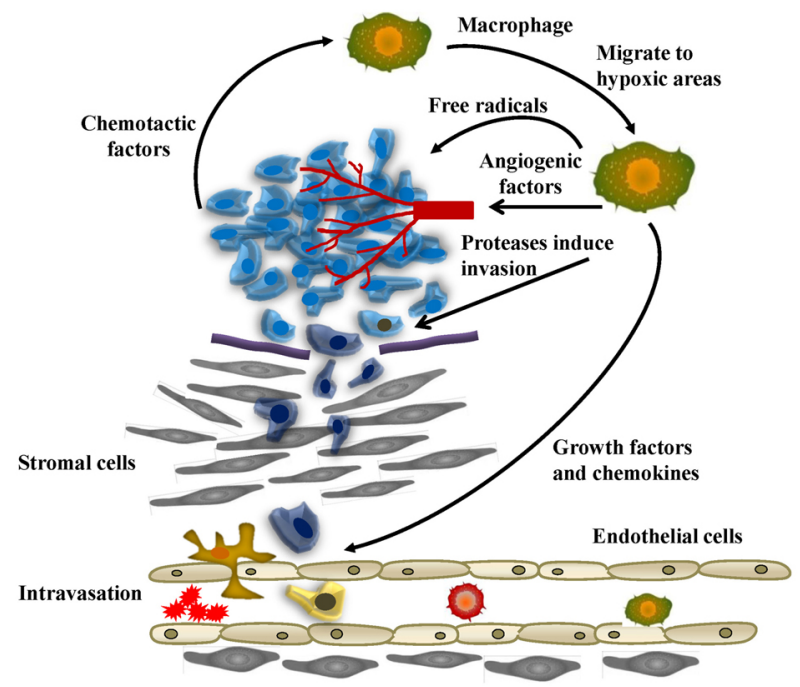

Fig. 4. Functions of tumor associated macrophages during tumor cell migration and invasion. Macrophages migrate to hypoxic areas and in turn stimulate angiogenesis with the help of various angiogenic factors. TAMs also promote invasion through the secretion of proteases. Several growth factors and chemokines aid in promoting migration of tumor cells to the vessels, and TAMs can break down the basement membrane as well to promote intravasation.

\section{TAMs AS POTENTIAL DIAGNOSTIC AND PROGNOSTIC MARKERS}

TAMs in breast tumor microenvironments typically express four surface markers; receptors for Fc portion of IgG and C3, HLADR antigen, and a macrophage-associated antigen (Steele et al., 1985). CD68, the human homolog of macrosialin, has been widely used as a pan-macrophage marker. There are many antibodies that recognize CD68 including Ki-M6, Ki-M7, Y2/131 and Y1/82A, EBM11, KP1, Ki-M1P, and PG-M1 (Gottfried et al., 2008). Increased CD68 expression has been shown to correlate with high vascularity and nodal metastasis and reduced recurrence-free and survival in human breast cancer (Jubb et al., 2010; Leek et al., 1996). Mahmoud et al., showed that increased CD68 markers predicted worse breast cancer-specific survival and shorter disease-free interval (Mahmoud et al., 2011). Other markers such as estrogen receptors (ER), progesterone receptor (PR), and human epidermal growth factor 2 (HER2) give a positive prognosis and were specifically designed to aid in therapy. However, it is not known how TAMs are associated with ER/PR/HER2 and thus more research must be conducted on the relationship between them before suggesting it as a possible treatment option. TAMs have also been shown to interfere with chemotherapy for breast cancer by releasing chemo-resistance factors or regulating the drugresistance of cancer stem cells.

Since CD68 staining stains both M2 and M1 macrophages, CD68 cannot be used by itself to predict overall survival (Jubb et al., 2010; Mahmoud et al., 2011; Tsutsui et al., 2005). Thus other TAM-associated markers such as CD163, VEGF, HIFs markers, proliferating cellular nuclear antigen (PCNA), ferritin light chain (FTL), and CCL-18 have been proposed as possible options to use for detection of TAMs along with CD68. CD163 has been shown to be primarily expressed by M2 macrophages and thus has been associated with worse characteristics (Me- drek et al., 2012). VEGF and EGFR are involved in macrophage infiltration in human breast cancer (Leek et al., 2000). VEGF, as noted previously, recruits more macrophages to the tumor microenvironment. TAMs with PCNA have been associated with high-grade, HR-negative breast cancers with an increased risk of recurrence and decreased overall survival in human breast cancers (Campbell et al., 2010; Mukhtar et al., 2011a). FTL stored in M2 macrophages indicates an aggressive phenotype in node-negative breast cancer patients. CCL18 is abundantly produced by breast cancer TAMs and is associated with metastasis and reduced patient survival. The counts predicted disease stage, histological grade, and lymph node and distant metastasis (Chen et al., 2011). Recent studies have indicated that CCL18 is a new and promising biomarker for cancer diagnosis and treatment.

\section{POSSIBLE TREATMENT STRATEGIES USING VARIOUS PROTEINS AND SMALL MOLECULES}

Tumor suppressors act in a variety of ways including inducing cell-cycle arrest, senescence, or apoptosis. Retinoblastoma protein $(\mathrm{Rb})$ plays a role in cell cycle control, differentiation, and inhibition of oncogenic transformation in addition to activation of $\mathrm{NF}-\mathrm{kB}$ pathway. Promyelocytic leukemia protein (PML) plays a role in tumorigenesis, DNA damage, senescence, apoptosis, and protein degradation. P53 plays a role in ribosome biogenesis, aging control, cell cycle arrest, and apoptosis. P53 also regulates MCP-1/CCL2. ARF, interestingly, is one of the most frequently mutated genes in human cancer (Sharpless, 2005). ARF activates p53 and inhibits ribosomal RNA processing and transcriptional factors that induce proliferation. ARF activates p53 by displacing Mdm2 in the nucleolus (Pomerantz et al., 1998; Stott et al., 1998), and inhibits ribosomal RNA processing and transcriptional factors that induce proliferation (Kuo et al., 2003; Martelli et al., 2001; Qi et al., 2004; Sugimoto et al., 2003). ARF has a protective effect against viral infection by interacting with cell proliferation nucleophosmin (NPM) and activating dsRNA-dependent protein kinase (PKR) (Garcia et al., 2006). ARF may even modulate M2 polarization of macrophages. ARF-deficient macrophages show less leukocyte recruitment and decreased ability to produce pro-inflammatory properties. E2F1 is increased in ARF-deficient mice which have been shown to be anti-inflammatory and immunosuppressive which impaired the signaling of the NF-кB pathway. On the other hand, it has been shown to be deleted in some cancers thus more research must be conducted to further elucidate ARF's function and effectiveness as a target for possible gene therapy.

Other methods have been investigated in order to interrupt or decrease macrophage recruitment to tumor microenvironments. Leuschner et al. used lipid nanoparticles containing siRNA to interrupt the CCL2-CCR2 interaction in order to disrupt macrophage recruitment. Using this method, they showed that the TAM infiltration was decreased (Leavy, 2011; Leuschner et al., 2011; Shantsila et al., 2011). Deletion of the CSFR1 gene reduced macrophage recruitment as well but only in resident tissue macrophages under normal conditions (MacDonald et al., 2010). Denardo et al. showed that using the PlexxiKon inhibitor, which inhibits CSFR1, along with cKit and PDGFR improved overall survival in mouse mammary carcinoma models (Denardo et al., 2011; Hume and MacDonald, 2011). Dijkgraaf et al. showed that blocking NF-kB signaling stopped platinum chemotherapy's effect of increased IL-6 and PGE2 causing more M2 differentiation. Thus anti-IL-6 therapy is another recom- 
mended route for therapies (Dijkgraaf et al., 2013). Other approaches include inhibition of GM-CSF in vivo and decreased VEGF and CCL-5 as ways to reduce monocyte recruitment (Bayne et al., 2012; Elbarghati et al., 2008; Pylayeva-Gupta et al., 2012). Hystidine-rich glycoprotein (HRG) has been shown to have anti-tumor mechanisms in breast, pancreatic, and fibrosarcoma murine models. Although there were no significant differences in TAM accumulation, the tumor volume was significantly decreased. Thus, HRG may be reducing M2 differentiation as levels of CXCL9 and IFN- $\beta$ are increased, which is a characteristic for M1 macrophages (Rolny et al., 2011). CD40 has also been used to make macrophages attain the classical M1 phenotype (Beatty et al., 2011; Chan et al., 2010).

One way to directly target macrophage phenotype differentiation in tumor microenvironments is by targeting the NF- $\mathrm{KB}$ pathway. This was done by inhibiting IKK $\beta$, the main activator of NF-kB in murine models. This led to reduced tumor volume (Hayakawa et al., 2009). Another method to reduce tumor survival is to reprogram the TME to impair tumor growth only. This can be accomplished by using antibodies such as ipilimumab which targets CTLA- 4 activating T cells, nivolumab, lambrolizumab, and CD40 targeted antibodies. Nivolumab targets the PD1 receptor causing apoptosis, while lambrolizumab is a blocking antibody for the PD1 ligand (Hamid et al., 2013; Hodi et al., 2010; Hwu, 2010; Restifo et al., 2012; Sharma et al., 2011; Vonderheide and Glennie, 2013; Wolchok et al., 2013). Combining these strategies may reduce tumor cells' evasion of the immune response and help destroy them. All of these methods have been somewhat effective and resulted in greater overall survival.

Therapeutic treatments for hepatocellular carcinoma $(\mathrm{HCC})$ that target TAMs have focused on inhibition of recruitment and/or polarization of M2 macrophages, inhibition of angiogenic and tissue remodeling, and inhibition of TAMs' immunosuppressive effects. Clodronate-encapsulated liposomes or aminobisphosphonates knock down macrophages in vivo but have also been shown to reduce angiogenesis and tumor progression. Researchers have also attempted to prevent M2 polarization or to convert them from M2 to M1. This was attempted by using the CpG immunostimulatory oligonucleotide and anti-IL10 receptor which caused macrophages to turn from M2 to M1 (Vicari et al., 2002). TAMs lacking STAT6 also display an M1 phenotype which can lead to further possibilities to prevent M2 polarization. CCL2/MCP-1 were discovered to have antitumor effects by using suicide gene therapy as well (Kakinoki et al., 2010; Tsuchiyama et al., 2008).

\section{BISPHOSPHONATES AS THERAPEUTIC MODALITIES}

Bisphosphonates are stable inorganic analogs of pyrophosphonate in which the central oxygen atom is replaced with a carbon atom. They are common in the treatment of many bone diseases such as cancer-induced bone disease, Paget's disease, and osteoporosis. There are two types of bisphosphonates: nitrogen-containing (N-BP) and non-nitrogen containing (non N-BP) which are characterized by the presence of a nitrogen atom on the R2 side chain (Rodan and Fleisch, 1996; Stresing et al., 2007; Winter and Coleman, 2009). Non N-BPs inhibit the conversion of ATP to ADP which causes mitochondrial dysfunction leading to apoptosis. N-BPs alter protein prenylation by inhibiting farnesyldiphosphonate (FPP) synthase which is important for the mevalonate pathway in eukaryotic cells (Green, 2002; Luckman et al., 1998; Monkkonen et al., 2006; Moreau et al., 2007; Stern, 2007).
To target TAMs in breast cancer, N-BPs are utilized. They interfere with the process of PTHrP, prostaglandin-E, and interleukins stimulating RANKL causing osteoclast progression which in turn causes bone resorption leading to release of TGF$\beta$ helping tumor cells proliferate and grow. Specifically, they interfere with the bone resorption step in this cycle (Mundy, 2002). N-BPs have also been shown to directly affect tumors by reducing tumor cell proliferation, adhesion, migration, invasion, and angiogenesis while increasing apoptosis (Boissier et al., 1997; 2000; Fromigue et al., 2000; Hiraga et al., 2004; Senaratne et al., 2000; 2002; van der Pluijm et al., 1996). Biphosphonates can also directly target macrophages due to their similarities with osteoclasts. Using them has been shown to inhibit macrophage proliferation, migration, invasion, and cause apoptosis. They can also inhibit MMP-9 as shown in vivo and in vitro and inhibit VEGF, and thereby angiogenesis and polarization to M2 macrophages. This effect, in turn, resulted in decreased tumor sizes and growth (Coscia et al., 2009; Gabrilovich and Nagaraj, 2009; Mantovani et al., 2002). Other studies have shown the usage of N-BPs have resulted in similar results, presenting a promising therapeutic treatment for various cancers.

\section{CONCLUSION}

Much research has been completed elucidating the effects of TAMs in cancer. It has been shown that TAMs have a generally pro-tumorigenic effect. With this knowledge, it is possible to determine new therapies targeting TAMs and using them against the tumor to reduce volume and stunt tumor growth. A few proteins such as Rb, PML, and p53 act as tumor suppressors allowing for modulation of the proteins in an attempt to curb tumor growth. A viable and promising option is to modulate ARF, one of the most commonly mutated genes in cancer, to activate $\mathrm{p53}$. This method has been shown to be promising, but more research must be completed. Directly targeting TAMs by reducing monocyte recruitment is another feasible option. This may be accomplished by interrupting the CCL2-CCR2 interaction. Another method to accomplish this is to downregulate GM-CSF, a crucial component used to recruit monocytes to the tumor. Similarly, it may be more feasible to control M2 differentiation by upregulating HRG or CD-40 to cause macrophages to assume the M1 phenotype, associated with antitumorigenic effects. The NF- $\mathrm{BB}$ pathway can also be targeted by inhibiting it with IKK $\beta$ reducing M2 differentiation. N-BPs have also been introduced as a novel idea to decrease tumor growth $\mathrm{N}$-BPs were shown to interfere in tumor cell proliferation, adhesion, migration, invasion, and angiogenesis while increasing apoptosis. In addition, N-BPs can inhibit MMP-9 and VEGF resulting in less M2 polarization and decreased angiogenesis.

Research on each of the aforementioned methods seems to indicate that they are all viable methods in the fight against cancer. More research must be completed to confirm their effects and usefulness in fighting tumors by attacking TAMs. It is clear, however, that progress is being made and novel methods to fighting cancer are on the horizon.

\section{ACKNOWLEDGMENTS}

We would like to thank LSU School of Medicine and LACaTS for financial support.

\section{REFERENCES}

Akaogi, J., Yamada, H., Kuroda, Y., Nacionales, D.C., Reeves, W.H. and Satoh, M. (2004). Prostaglandin E2 receptors EP2 and EP4 are up-regulated in peritoneal macrophages and joints of pris- 
tane-treated mice and modulate TNF-alpha and IL- 6 production. J. Leukoc. Biol. 76, 227-236.

Allavena, P., Sica, A., Solinas, G., Porta, C., and Mantovani, A. (2008). The inflammatory micro-environment in tumor progression: the role of tumor-associated macrophages. Crit. Rev. Oncol. Hematol. 66, 1-9.

Bayne, L.J., Beatty, G.L., Jhala, N., Clark, C.E., Rhim, A.D., Stanger, B.Z., and Vonderheide, R.H. (2012). Tumor-derived granulocyte-macrophage colony-stimulating factor regulates myeloid inflammation and $\mathrm{T}$ cell immunity in pancreatic cancer. Cancer Cell 21, 822-835

Beatty, G.L., Chiorean, E.G., Fishman, M.P., Saboury, B., Teitelbaum, U.R., Sun, W., Huhn, R.D., Song, W., Li, D., Sharp, L.L., et al. (2011). CD40 agonists alter tumor stroma and show efficacy against pancreatic carcinoma in mice and humans. Science 331, 1612-1616.

Biswas, S.K., and Mantovani, A. (2010). Macrophage plasticity and interaction with lymphocyte subsets: cancer as a paradigm. Nat. Immunol. 11, 889-896.

Boissier, S., Magnetto, S., Frappart, L., Cuzin, B., Ebetino, F.H., Delmas, P.D., and Clezardin, P. (1997). Bisphosphonates inhibit prostate and breast carcinoma cell adhesion to unmineralized and mineralized bone extracellular matrices. Cancer Res. 57, 3890-3894.

Boissier, S., Ferreras, M., Peyruchaud, O., Magnetto, S., Ebetino, F.H., Colombel, M., Delmas, P., Delaisse, J.M., and Clezardin, P. (2000). Bisphosphonates inhibit breast and prostate carcinoma cell invasion, an early event in the formation of bone metastases. Cancer Res. 60, 2949-2954.

Bronte, V., and Zanovello, P. (2005). Regulation of immune responses by L-arginine metabolism. Nat. Rev. Immunol. 5, 641654

Campbell, M.J., Tonlaar, N.Y., Garwood, E.R., Huo, D., Moore, D.H., Khramtsov, A.I., Au, A., Baehner, F., Chen, Y., Malaka, D.O., et al. (2010). Proliferating macrophages associated with high grade, hormone receptor negative breast cancer and poor clinical outcome. Breast Cancer Res. Treat 128, 703-711.

Chan, L.L., Cheung, B.K., Li, J.C., and Lau, A.S. (2010). A role for STAT3 and cathepsin S in IL-10 down-regulation of IFNgamma-induced MHC class II molecule on primary human blood macrophages. J. Leukoc. Biol. 88, 303-311.

Chang, C.I., Liao, J.C., and Kuo, L. (2001). Macrophage arginase promotes tumor cell growth and suppresses nitric oxidemediated tumor cytotoxicity. Cancer Res. 61, 1100-1106.

Chen, J., Yao, Y., Gong, C., Yu, F., Su, S., Liu, B., Deng, H., Wang, F., Lin, L., Yao, H., et al. (2011). CCL18 from tumor-associated macrophages promotes breast cancer metastasis via PITPNM3. Cancer Cell 19, 541-555.

Chen, C., Shen, Y., Qu, Q.X., Chen, X.Q., Zhang, X.G., and Huang, J.A. (2012). Induced expression of B7-H3 on the lung cancer cells and macrophages suppresses T-cell mediating anti-tumor immune response. Exp. Cell Res. 319, 96-102.

Chiodoni, C., Colombo, M.P., and Sangaletti, S. (2010). Matricellular proteins: from homeostasis to inflammation, cancer, and metastasis. Cancer Metastasis Rev. 29, 295-307.

Coffelt, S.B., Hughes, R., and Lewis, C.E. (2009). Tumorassociated macrophages: effectors of angiogenesis and tumor progression. Biochim. Biophys. Acta 1796, 11-18.

Coscia, M., Quaglino, E., lezzi, M., Curcio, C., Pantaleoni, F., Riganti, C., Holen, I., Monkkonen, H., Boccadoro, M., Forni, G., et al. (2009). Zoledronic acid repolarizes tumour-associated macrophages and inhibits mammary carcinogenesis by targeting the mevalonate pathway. J. Cell. Mol. Med. 14, 2803-2815.

DeNardo, D.G., Barreto, J.B., Andreu, P., Vasquez, L., Tawfik, D., Kolhatkar, N., and Coussens, L.M. (2009). CD4(+) T cells regulate pulmonary metastasis of mammary carcinomas by enhancing protumor properties of macrophages. Cancer Cell 16, 91102

Denardo, S.J., Wen, X., Handberg, E.M., Bairey Merz, C.N., Sopko, G.S., Cooper-Dehoff, R.M., and Pepine, C.J. (2011). Effect of phosphodiesterase type 5 inhibition on microvascular coronary dysfunction in women: a Women's Ischemia Syndrome Evaluation (WISE) ancillary study. Clin. Cardiol. 34, 483-487.

Dijkgraaf, E.M., Heusinkveld, M., Tummers, B., Vogelpoel, L.T., Goedemans, R., Jha, V., Nortier, J.W., Welters, M.J., Kroep, J.R., and van der Burg, S.H. (2013). Chemotherapy alters mo- nocyte differentiation to favor generation of cancer-supporting M2 macrophages in the tumor microenvironment. Cancer Res. 73, 2480-2492

Doedens, A.L., Stockmann, C., Rubinstein, M.P., Liao, D., Zhang, N., DeNardo, D.G., Coussens, L.M., Karin, M., Goldrath, A.W., and Johnson, R.S. (2010). Macrophage expression of hypoxiainducible factor-1 alpha suppresses T-cell function and promotes tumor progression. Cancer Res. 70, 7465-7475.

Egeblad, M., and Werb, Z. (2002). New functions for the matrix metalloproteinases in cancer progression. Nat. Rev. Cancer 2, 161-174.

Elbarghati, L., Murdoch, C., and Lewis, C.E. (2008). Effects of hypoxia on transcription factor expression in human monocytes and macrophages. Immunobiology 213, 899-908.

Erler, J.T., Bennewith, K.L., Cox, T.R., Lang, G., Bird, D., Koong, A. Le, Q.T., and Giaccia, A.J. (2009). Hypoxia-induced lysyl oxidase is a critical mediator of bone marrow cell recruitment to form the premetastatic niche. Cancer Cell 15, 35-44.

Fong, C.H., Bebien, M., Didierlaurent, A., Nebauer, R., Hussell, T., Broide, D., Karin, M., and Lawrence, T. (2008). An antiinflammatory role for IKKbeta through the inhibition of "classical" macrophage activation. J. Exp. Med. 205, 1269-1276.

Fromigue, O., Lagneaux, L., and Body, J.J. (2000). Bisphosphonates induce breast cancer cell death in vitro. J. Bone Miner Res. $15,2211-2221$.

Gabrilovich, D.I., and Nagaraj, S. (2009). Myeloid-derived suppressor cells as regulators of the immune system. Nat. Rev. Immunol. 9, 162-174.

Galdiero, M.R., Bonavita, E., Barajon, I., Garlanda, C., Mantovani, A., and Jaillon, S. (2013). Tumor associated macrophages and neutrophils in cancer. Immunobiology 218, 1402-1410.

Garcia, M.A., Collado, M., Munoz-Fontela, C., Matheu, A., MarcosVillar, L., Arroyo, J., Esteban, M., Serrano, M., and Rivas, C. (2006). Antiviral action of the tumor suppressor ARF. EMBO J. 25, 4284-4292.

Giraudo, E., Inoue, M., and Hanahan, D. (2004). An aminobisphosphonate targets MMP-9-expressing macrophages and angiogenesis to impair cervical carcinogenesis. J. Clin. Invest. 114, 623-633.

Goede, V., Brogelli, L., Ziche, M., and Augustin, H.G. (1999). Induction of inflammatory angiogenesis by monocyte chemoattractant protein-1. Int. J. Cancer 82, 765-770.

Gordon, S. (2003). Alternative activation of macrophages. Nat. Rev. Immunol. 3, 23-35.

Gottfried, E., Kunz-Schughart, L.A., Weber, A., Rehli, M., Peuker A., Muller, A., Kastenberger, M., Brockhoff, G., Andreesen, R. and Kreutz, M. (2008). Expression of CD68 in non-myeloid cell types. Scand J. Immunol. 67, 453-463.

Green, J.R. (2002). Bisphosphonates in cancer therapy. Curr. Opin. Oncol. 14, 609-615.

Greten, F.R., Eckmann, L., Greten, T.F., Park, J.M., Li, Z.W., Egan, L.J., Kagnoff, M.F., and Karin, M. (2004). IKKbeta links inflammation and tumorigenesis in a mouse model of colitisassociated cancer. Cell 118, 285-296.

Hagemann, T., Wilson, J., Burke, F., Kulbe, H., Li, N.F., Pluddemann, A., Charles, K., Gordon, S., and Balkwill, F.R. (2006) Ovarian cancer cells polarize macrophages toward a tumorassociated phenotype. J. Immunol. 176, 5023-5032.

Hagemann, T., Lawrence, T., McNeish, I., Charles, K.A., Kulbe, H. Thompson, R.G., Robinson, S.C., and Balkwill, F.R. (2008). "Re-educating" tumor-associated macrophages by targeting NFkappaB. J. Exp. Med. 205, 1261-1268.

Hagemann, T., Biswas, S.K., Lawrence, T., Sica, A., and Lewis, C.E. (2009). Regulation of macrophage function in tumors: the multifaceted role of NF-kappaB. Blood 113, 3139-3146.

Hamid, O., Robert, C., Daud, A., Hodi, F.S., Hwu, W.J., Kefford, R., Wolchok, J.D., Hersey, P., Joseph, R.W., Weber, J.S., et al. (2013). Safety and tumor responses with lambrolizumab (antiPD-1) in melanoma. N Engl. J. Med. 369, 134-144.

Hanahan, D., and Weinberg, R.A. (2000). The hallmarks of cancer. Cell 100, 57-70.

Hayakawa, Y., Maeda, S., Nakagawa, H., Hikiba, Y., Shibata, W. Sakamoto, K., Yanai, A., Hirata, Y., Ogura, K., Muto, S., et al (2009). Effectiveness of IkappaB kinase inhibitors in murine colitis-associated tumorigenesis. J. Gastroenterol. 44, 935-943.

Heusinkveld, M., and van der Burg, S.H. (2011). Identification and 
manipulation of tumor associated macrophages in human cancers. J. Transl. Med. 9, 216.

Heusinkveld, M., de Vos van Steenwijk, P.J., Goedemans, R., Ramwadhdoebe, T.H., Gorter, A., Welters, M.J., van Hall, T., and van der Burg, S.H. (2011). M2 macrophages induced by prostaglandin E2 and IL-6 from cervical carcinoma are switched to activated M1 macrophages by CD4+ Th1 cells. J. Immunol. 187, 1157-1165.

Hiraga, T., Williams, P.J., Ueda, A., Tamura, D., and Yoneda, T. (2004). Zoledronic acid inhibits visceral metastases in the 4T1/luc mouse breast cancer model. Clin. Cancer Res. 10, 4559-4567

Hodi, F.S., O'Day, S.J., McDermott, D.F., Weber, R.W., Sosman, J.A., Haanen, J.B., Gonzalez, R., Robert, C., Schadendorf, D. Hassel, J.C., et al. (2010). Improved survival with ipilimumab in patients with metastatic melanoma. N Engl. J. Med. 363, 711723.

Huang, S., Van Arsdall, M., Tedjarati, S., McCarty, M., Wu, W., Langley, R., and Fidler, I.J. (2002). Contributions of stromal metalloproteinase-9 to angiogenesis and growth of human ovarian carcinoma in mice. J. Natl. Cancer Inst. 94, 1134-1142.

Hume, D.A., and MacDonald, K.P. (2011). Therapeutic applications of macrophage colony-stimulating factor-1 (CSF-1) and antagonists of CSF-1 receptor (CSF-1R) signaling. Blood 119, 18101820.

Hwu, P. (2010). Treating cancer by targeting the immune system. N Engl. J. Med. 363, 779-781.

Imtiyaz, H.Z., Williams, E.P., Hickey, M.M., Patel, S.A., Durham, A.C., Yuan, L.J., Hammond, R., Gimotty, P.A., Keith, B., and Simon, M.C. (2010). Hypoxia-inducible factor 2alpha regulates macrophage function in mouse models of acute and tumor inflammation. J. Clin. Invest. 120, 2699-2714

Ji, R.C. (2011). Macrophages are important mediators of either tumor- or inflammation-induced lymphangiogenesis. Cell. Mol. Life Sci. 69, 897-914.

Joyce, J.A., and Pollard, J.W. (2009). Microenvironmental regulation of metastasis. Nat. Rev. Cancer 9, 239-252

Jubb, A.M., Soilleux, E.J., Turley, H., Steers, G., Parker, A., Low, I., Blades, J., Li, J.L., Allen, P., Leek, R., et al. (2010). Expression of vascular notch ligand delta-like 4 and inflammatory markers in breast cancer. Am. J. Pathol. 176, 2019-2028.

Kakinoki, K., Nakamoto, Y., Kagaya, T., Tsuchiyama, T., Sakai, Y., Nakahama, T., Mukaida, N., and Kaneko, S. (2010). Prevention of intrahepatic metastasis of liver cancer by suicide gene therapy and chemokine ligand 2/monocyte chemoattractant protein-1 delivery in mice. J. Gene Med. 12, 1002-1013.

Kambayashi, T., Alexander, H.R., Fong, M., and Strassmann, G. (1995). Potential involvement of IL-10 in suppressing tumorassociated macrophages. Colon-26-derived prostaglandin E2 inhibits TNF-alpha release via a mechanism involving IL-10. J. Immunol. 154, 3383-3390.

Kim, J., Modlin, R.L., Moy, R.L., Dubinett, S.M., McHugh, T., Nickoloff, B.J., and Uyemura, K. (1995). IL-10 production in cutaneous basal and squamous cell carcinomas. A mechanism for evading the local $\mathrm{T}$ cell immune response. J. Immunol. 155, 2240-2247.

Kim, S., Takahashi, H., Lin, W.W., Descargues, P., Grivennikov, S., Kim, Y., Luo, J.L., and Karin, M. (2009). Carcinoma-produced factors activate myeloid cells through TLR2 to stimulate metastasis. Nature 457, 102-106.

Knowles, H.J., and Harris, A.L. (2007). Macrophages and the hypoxic tumour microenvironment. Front Biosci. 12, 4298-4314.

Kuo, M.L., Duncavage, E.J., Mathew, R., den Besten, W., Pei, D., Naeve, D., Yamamoto, T., Cheng, C., Sherr, C.J., and Roussel, M.F. (2003). Arf induces p53-dependent and -independent antiproliferative genes. Cancer Res. 63, 1046-1053.

Kurahara, H., Takao, S., Maemura, K., Mataki, Y., Kuwahata, T., Maeda, K., Sakoda, M., lino, S., Ishigami, S., Ueno, S., et al (2012). M2-polarized tumor-associated macrophage infiltration of regional lymph nodes is associated with nodal lymphangiogenesis and occult nodal involvement in pNO pancreatic cancer. Pancreas 42, 155-159.

Lamagna, C., Aurrand-Lions, M., and Imhof, B.A. (2006). Dual role of macrophages in tumor growth and angiogenesis. J. Leukoc. Biol. 80, 705-713.

Lang, R., Patel, D., Morris, J.J., Rutschman, R.L., and Murray, P.J.
(2002). Shaping gene expression in activated and resting primary macrophages by IL-10. J. Immunol. 169, 2253-2263.

Lawrence, T., Gilroy, D.W., Colville-Nash, P.R., and Willoughby, D.A. (2001). Possible new role for NF-kappaB in the resolution of inflammation. Nat. Med. 7, 1291-1297.

Leavy, O. (2011). Immunotherapy: Stopping monocytes in their tracks. Nat. Rev. Immunol. 11, 715.

Leek, R.D., Lewis, C.E., Whitehouse, R., Greenall, M., Clarke, J., and Harris, A.L. (1996). Association of macrophage infiltration with angiogenesis and prognosis in invasive breast carcinoma. Cancer Res. 56, 4625-4629.

Leek, R.D., Hunt, N.C., Landers, R.J., Lewis, C.E., Royds, J.A., and Harris, A.L. (2000). Macrophage infiltration is associated with VEGF and EGFR expression in breast cancer. J. Pathol. 190, 430-436.

Leek, R.D., Talks, K.L., Pezzella, F., Turley, H., Campo, L., Brown, N.S., Bicknell, R., Taylor, M., Gatter, K.C., and Harris, A.L. (2002). Relation of hypoxia-inducible factor-2 alpha (HIF-2 alpha) expression in tumor-infiltrative macrophages to tumor angiogenesis and the oxidative thymidine phosphorylase pathway in Human breast cancer. Cancer Res. 62, 1326-1329.

Leuschner, F., Dutta, P., Gorbatov, R., Novobrantseva, T.I., Donahoe, J.S., Courties, G., Lee, K.M., Kim, J.I., Markmann, J.F., Marinelli, B., et al. (2011). Therapeutic siRNA silencing in inflammatory monocytes in mice. Nat. Biotechnol. 29, 1005-1010.

Luckman, S.P., Hughes, D.E., Coxon, F.P., Graham, R., Russell, G. and Rogers, M.J. (1998). Nitrogen-containing bisphosphonates inhibit the mevalonate pathway and prevent post-translational prenylation of GTP-binding proteins, including Ras. J. Bone Miner Res. 13, 581-589.

Luedde, T., Beraza, N., Kotsikoris, V., van Loo, G., Nenci, A., De Vos, R., Roskams, T., Trautwein, C., and Pasparakis, M. (2007) Deletion of NEMO/IKKgamma in liver parenchymal cells causes steatohepatitis and hepatocellular carcinoma. Cancer Cell 11, 119-132.

MacDonald, K.P., Palmer, J.S., Cronau, S., Seppanen, E., Olver, S. Raffelt, N.C., Kuns, R., Pettit, A.R., Clouston, A., Wainwright, B. et al. (2010). An antibody against the colony-stimulating factor 1 receptor depletes the resident subset of monocytes and tissueand tumor-associated macrophages but does not inhibit inflammation. Blood 116, 3955-3963.

Maeda, S., Kamata, H., Luo, J.L., Leffert, H., and Karin, M. (2005). IKKbeta couples hepatocyte death to cytokine-driven compensatory proliferation that promotes chemical hepatocarcinogenesis. Cell 121, 977-990

Mahmoud, S.M., Lee, A.H., Paish, E.C., Macmillan, R.D., Ellis, I.O., and Green, A.R. (2011). Tumour-infiltrating macrophages and clinical outcome in breast cancer. J. Clin. Pathol. 65 , 159-163.

Mantovani, A. (2009). Cancer: inflaming metastasis. Nature 457, 36-37.

Mantovani, A., and Sica, A. (2010). Macrophages, innate immunity and cancer: balance, tolerance, and diversity. Curr. Opin. Immunol. 22, 231-237

Mantovani, A., Sozzani, S., Locati, M., Allavena, P., and Sica, A. (2002). Macrophage polarization: tumor-associated macrophages as a paradigm for polarized M2 mononuclear phagocytes. Trends Immunol. 23, 549-555.

Mantovani, A., Allavena, P., Sica, A., and Balkwill, F. (2008). Cancer-related inflammation. Nature 454, 436-444.

Martelli, F., Hamilton, T., Silver, D.P., Sharpless, N.E., Bardeesy, N. Rokas, M., DePinho, R.A., Livingston, D.M., and Grossman, S.R (2001). p19ARF targets certain E2F species for degradation. Proc. Natl. Acad. Sci. USA 98, 4455-4460.

Martinez, F.O., Helming, L., and Gordon, S. (2009). Alternative activation of macrophages: an immunologic functional perspective. Annu. Rev. Immunol. 27, 451-483.

Medrek, C., Ponten, F., Jirstrom, K., and Leandersson, K. (2012) The presence of tumor associated macrophages in tumor stroma as a prognostic marker for breast cancer patients. BMC Cancer 12, 306.

Monkkonen, H., Auriola, S., Lehenkari, P., Kellinsalmi, M., Hassinen I.E., Vepsalainen, J., and Monkkonen, J. (2006). A new endogenous ATP analog (Apppl) inhibits the mitochondrial adenine nucleotide translocase (ANT) and is responsible for the apoptosis induced by nitrogen-containing bisphosphonates. $\mathrm{Br}$. J. Pharmacol. 147, 437-445. 
Moore, K.W., de Waal Malefyt, R., Coffman, R.L., and O'Garra, A. (2001). Interleukin-10 and the interleukin-10 receptor. Annu. Rev. Immunol. 19, 683-765.

Moreau, M.F., Guillet, C., Massin, P., Chevalier, S., Gascan, H., Basle, M.F., and Chappard, D. (2007). Comparative effects of five bisphosphonates on apoptosis of macrophage cells in vitro. Biochem. Pharmacol. 73, 718-723.

Movahedi, K., Laoui, D., Gysemans, C., Baeten, M., Stange, G., Van den Bossche, J., Mack, M., Pipeleers, D., In't Veld, P., De Baetselier, P., et al. (2010). Different tumor microenvironments contain functionally distinct subsets of macrophages derived from Ly6C(high) monocytes. Cancer Res. 70, 5728-5739.

Mukhtar, R.A., Moore, A.P., Nseyo, O., Baehner, F.L., Au, A., Moore, D.H., Twomey, P., Campbell, M.J., and Esserman, L.J. (2011a). Elevated PCNA+ tumor-associated macrophages in breast cancer are associated with early recurrence and nonCaucasian ethnicity. Breast Cancer Res. Treat 130, 635-644.

Mundy, G.R. (2002). Metastasis to bone: causes, consequences and therapeutic opportunities. Nat. Rev. Cancer 2, 584-593.

Murdoch, C., and Lewis, C.E. (2005). Macrophage migration and gene expression in response to tumor hypoxia. Int. J. Cancer 117, 701-708

Murdoch, C., Giannoudis, A., and Lewis, C.E. (2004). Mechanisms regulating the recruitment of macrophages into hypoxic areas of tumors and other ischemic tissues. Blood 104, 2224-2234.

Murdoch, C., Muthana, M., Coffelt, S.B., and Lewis, C.E. (2008). The role of myeloid cells in the promotion of tumour angiogenesis. Nat. Rev. Cancer 8, 618-631.

Murray, P.J., and Wynn, T.A. (2011). Obstacles and opportunities for understanding macrophage polarization. J. Leukoc. Biol. 89, 557-563.

Naugler, W.E., Sakurai, T., Kim, S., Maeda, S., Kim, K., Elsharkawy, A.M., and Karin, M. (2007). Gender disparity in liver cancer due to sex differences in MyD88-dependent IL-6 production. Science $317,121-124$

Obeid, E., Nanda, R., Fu, Y.X., and Olopade, O.I. (2013). The role of tumor-associated macrophages in breast cancer progression (review). Int. J. Oncol. 43, 5-12.

Pikarsky, E., Porat, R.M., Stein, I., Abramovitch, R., Amit, S., Kasem, S., Gutkovich-Pyest, E., Urieli-Shoval, S., Galun, E., and Ben-Neriah, Y. (2004). NF-kappaB functions as a tumour promoter in inflammation-associated cancer. Nature 431, 461-466.

Pollard, J.W. (2004). Tumour-educated macrophages promote tumour progression and metastasis. Nat. Rev. Cancer 4, 71-78.

Pollard, J.W. (2009). Trophic macrophages in development and disease. Nat. Rev. Immunol. 9, 259-270.

Pomerantz, J., Schreiber-Agus, N., Liegeois, N.J., Silverman, A., Alland, L., Chin, L., Potes, J., Chen, K., Orlow, I., Lee, H.W., et al. (1998). The Ink4a tumor suppressor gene product, p19Arf, interacts with MDM2 and neutralizes MDM2's inhibition of p53. Cell 92, 713-723.

Porta, C., Riboldi, E., and Sica, A. (2011). Mechanisms linking pathogens-associated inflammation and cancer. Cancer Lett. 305, 250-262.

Pylayeva-Gupta, Y., Lee, K.E., Hajdu, C.H., Miller, G., and Bar-Sagi, D. (2012). Oncogenic Kras-induced GM-CSF production promotes the development of pancreatic neoplasia. Cancer Cell 21, 836-847.

Qi, Y., Gregory, M.A., Li, Z., Brousal, J.P., West, K., and Hann, S.R. (2004). p19ARF directly and differentially controls the functions of c-Myc independently of p53. Nature 431, 712-717.

Qing, W., Fang, W.Y., Ye, L., Shen, L.Y., Zhang, X.F., Fei, X.C., Chen, X., Wang, W.Q., Li, X.Y., Xiao, J.C., et al. (2012). Density of tumor-associated macrophages correlates with lymph node metastasis in papillary thyroid carcinoma. Thyroid 22, 905-910.

Raica, M., Cimpean, A.M., and Ribatti, D. (2009). Angiogenesis in pre-malignant conditions. Eur. J. Cancer 45, 1924-1934.

Rankin, E.B., and Giaccia, A.J. (2008). The role of hypoxiainducible factors in tumorigenesis. Cell Death Differ 15, 678-685.

Restifo, N.P. Dudley, M.E., and Rosenberg, S.A. (2012). Adoptive immunotherapy for cancer: harnessing the $T$ cell response. Nat. Rev. Immunol. 12, 269-281.

Rius, J., Guma, M., Schachtrup, C., Akassoglou, K., Zinkernagel, A.S., Nizet, V., Johnson, R.S., Haddad, G.G., and Karin, M. (2008). NF-kappaB links innate immunity to the hypoxic response through transcriptional regulation of HIF-1alpha. Nature
453, 807-811.

Rodan, G.A., and Fleisch, H.A. (1996). Bisphosphonates: mechanisms of action. J. Clin. Invest. 97, 2692-2696.

Rolny, C., Mazzone, M., Tugues, S., Laoui, D., Johansson, I., CouIon, C., Squadrito, M.L., Segura, I., Li, X., Knevels, E., et al. (2011). HRG inhibits tumor growth and metastasis by inducing macrophage polarization and vessel normalization through downregulation of PIGF. Cancer Cell 19, 31-44.

Senaratne, S.G., Pirianov, G., Mansi, J.L., Arnett, T.R., and Colston, K.W. (2000). Bisphosphonates induce apoptosis in human breast cancer cell lines. Br J. Cancer 82, 1459-1468.

Senaratne, S.G., Mansi, J.L., and Colston, K.W. (2002). The bisphosphonate zoledronic acid impairs Ras membrane [correction of impairs membrane] localisation and induces cytochrome $\mathrm{c}$ release in breast cancer cells. Br J. Cancer 86, 1479-1486.

Shantsila, E., Wrigley, B., Tapp, L., Apostolakis, S., Montoro-Garcia S., Drayson, M.T., and Lip, G.Y. (2011). Immunophenotypic characterization of human monocyte subsets: possible implications for cardiovascular disease pathophysiology. J. Thromb. Haemost. 9, 1056-1066.

Sharma, P., Wagner, K., Wolchok, J.D., and Allison, J.P. (2011). Novel cancer immunotherapy agents with survival benefit: recent successes and next steps. Nat. Rev. Cancer 11, 805-812.

Sharpless, N.E. (2005). INK4a/ARF: a multifunctional tumor suppressor locus. Mutat. Res. 576, 22-38.

Shen, Z., Seppanen, H., Vainionpaa, S., Ye, Y., Wang, S., Mustonen, H., and Puolakkainen, P. (2012). IL10, IL11, IL18 are differently expressed in CD14+ TAMs and play different role in regulating the invasion of gastric cancer cells under hypoxia. Cytokine 59, 352-357.

Shirabe, K., Mano, Y., Muto, J., Matono, R., Motomura, T., Toshima T., Takeishi, K., Uchiyama, H., Yoshizumi, T., Taketomi, A., et al. (2011). Role of tumor-associated macrophages in the progression of hepatocellular carcinoma. Surg. Today 42, 1-7.

Sica, A., Saccani, A., Bottazzi, B., Polentarutti, N., Vecchi, A., van Damme, J., and Mantovani, A. (2000). Autocrine production of IL-10 mediates defective IL-12 production and NF-kappa B activation in tumor-associated macrophages. J. Immunol. 164, 762767

Siveen, K.S., and Kuttan, G. (2009). Role of macrophages in tumour progression. Immunol. Lett. 123, 97-102.

Steele, R.J., Brown M., and Eremin O. (1985). Characterisation of macrophages infiltrating human mammary carcinomas. Br. J. Cancer 51, 135-138.

Stern, P.H. (2007). Antiresorptive agents and osteoclast apoptosis. J. Cell. Biochem. 101, 1087-1096.

Stetler-Stevenson, W.G., and Yu, A.E. (2001). Proteases in invasion: matrix metalloproteinases. Semin. Cancer Biol. 11, 143152

Stott, F.J., Bates, S., James, M.C., McConnell, B.B., Starborg, M., Brookes, S., Palmero, I., Ryan, K., Hara, E., Vousden, K.H., et al. (1998). The alternative product from the human CDKN2A locus, p14(ARF), participates in a regulatory feedback loop with p53 and MDM2. EMBO J. 17, 5001-5014.

Stresing, V., Daubine, F., Benzaid, I., Monkkonen, H., and Clezardin, P. (2007). Bisphosphonates in cancer therapy. Cancer Lett. 257, 16-35.

Sugimoto, M., Kuo, M.L., Roussel, M.F., and Sherr, C.J. (2003). Nucleolar Arf tumor suppressor inhibits ribosomal RNA processing. Mol. Cell 11, 415-424.

Swain, S.M., and Arezzo, J.C. (2008). Neuropathy associated with microtubule inhibitors: diagnosis, incidence, and management. Clin. Adv. Hematol. Oncol. 6, 455-467.

Tsuchiyama, T., Nakamoto, Y., Sakai, Y., Mukaida, N., and Kaneko, S. (2008). Optimal amount of monocyte chemoattractant protein-1 enhances antitumor effects of suicide gene therapy against hepatocellular carcinoma by M1 macrophage activation. Cancer Sci. 99, 2075-2082.

Tsutsui, S., Yasuda, K., Suzuki, K., Tahara, K., Higashi, H., and Era S. (2005). Macrophage infiltration and its prognostic implications in breast cancer: the relationship with VEGF expression and microvessel density. Oncol. Rep. 14, 425-431.

van der Pluijm, G., Vloedgraven, H., van Beek, E., van der WeePals, L., Lowik, C., and Papapoulos, S. (1996). Bisphosphonates inhibit the adhesion of breast cancer cells to bone matrices in vitro. J. Clin. Invest. 98, 698-705. 
Vicari, A.P., Chiodoni, C., Vaure, C., Ait-Yahia, S., Dercamp, C., Matsos, F., Reynard, O., Taverne, C., Merle, P., Colombo, M.P., et al. (2002). Reversal of tumor-induced dendritic cell paralysis by $\mathrm{CpG}$ immunostimulatory oligonucleotide and anti-interleukin 10 receptor antibody. J. Exp. Med. 196, 541-549.

Vonderheide, R.H., and Glennie, M.J. (2013). Agonistic CD40 antibodies and cancer therapy. Clin. Cancer Res. 19, 1035-1043.

Wang, F.Q., So, J., Reierstad, S., and Fishman, D.A. (2005). Matrilysin (MMP-7) promotes invasion of ovarian cancer cells by activation of progelatinase. Int. J. Cancer 114, 19-31.

Winter, M.C., and Coleman, R.E. (2009). Bisphosphonates in breast cancer: teaching an old dog new tricks. Curr. Opin. Oncol. 21, 499-506.

Wolchok, J.D., Kluger, H., Callahan, M.K., Postow, M.A., Rizvi, N.A., Lesokhin, A.M., Segal, N.H., Ariyan, C.E., Gordon, R.A., Reed, K., et al. (2013). Nivolumab plus ipilimumab in advanced melanoma. N Engl. J. Med. 369, 122-133.
Wu, H., Xu, J.B., He, Y.L., Peng, J.J., Zhang, X.H., Chen, C.Q., Li, W., and Cai, S.R. (2012). Tumor-associated macrophages promote angiogenesis and lymphangiogenesis of gastric cancer. J. Surg. Oncol. 106, 462-468.

Ye, X.Z., Xu, S.L., Xin, Y.H., Yu, S.C., Ping, Y.F., Chen, L., Xiao, H.L., Wang, B., Yi, L., Wang, Q.L., et al. (2012). Tumorassociated microglia/macrophages enhance the invasion of glioma stem-like cells via TGF-beta1 signaling pathway. J. Immunol. 189, 444-453.

Zhao, J.J., Pan, K., Wang, W., Chen, J.G., Wu, Y.H., Lv, L., Li, J.J., Chen, Y.B., Wang, D.D., Pan, Q.Z., et al. (2012a). The prognostic value of tumor-infiltrating neutrophils in gastric adenocarcinoma after resection. PLoS One 7, e33655.

Zhao, Q., Kuang, D.M., Wu, Y., Xiao, X., Li, X.F., Li, T.J., and Zheng, L. (2012b). Activated CD69+ T cells foster immune privilege by regulating IDO expression in tumor-associated macrophages. J. Immunol. 188, 1117-1124. 